\title{
Um devir menor no currículo de filosofia
}

\author{
Un devenir menor en el currículo de filosofía
}

\author{
Francis Mary Soares Correia da Rosa \\ Doutoranda na Universidade Estadual da Bahia, Salvador, Bahia, Brasil. \\ francismrosa@hotmail.com \\ ORCID: http://orcid.org/0000-0003-0692-8275
}

\section{Lorena de Oliveira Asevedo}

Professora da Secretaria de Educação do Estado da Bahia, Vitória da Conquista, Bahia, Brasil. lory.asevedo@hotmail.com

Recebido em 18 de dezembro de 2017

Aprovado em 18 de junho de 2018

Publicado em 17 de agosto de 2018

RESUMO: A proposta desse artigo é discutir as possibilidades e experimentações do ensino de filosofia na educação básica, centrando-se no currículo proposto para o ensino oficial, a partir das noções de currículo menor e educação menor tematizadas por Silvio Gallo por meio da obra dos filósofos franceses G. Deleuze e F. Guattari. Busca-se por meio da revisão da literatura a respeito, considerações e diálogos possíveis ao ensino de filosofia como experiência cultural e pluriversal. Espera-se com tal discussão experenciar o conceito de currículo menor como uma aposta ética e filosofia para um ensino de filosofia condizente com um cenário de mudanças.

Palavras-chave: Currículo Menor; Ensino; Filosofia.

RESUMEN: La propuesta de este artículo es discutir las posibilidades y experimentaciones de la enseñanza de filosofía en la educación básica, centrándose en el currículo propuesto para la enseñanza oficial, a partir de las nociones de currículo menor y educación menor tematizadas por Silvio Gallo por medio de la obra de los filósofos franceses G. Deleuze y F. Guattari. Se busca por medio de la revisión de la literatura al respecto, consideraciones y diálogos posibles a la enseñanza de filosofía como experiencia cultural y pluriversal. Se espera con tal discusión experimentar el concepto de currículo menor como una apuesta ética y filosofía para una enseñanza de filosofía que concuerda con un escenario de cambios. Palabras-clave: Currículo Menor; Enseñanza; Filosofía.

\section{Um olhar sobre o ensino de filosofia no Brasil}

Ensinar a filosofar exige que se filosofe também. Que se tenha a coragem de pensar por conta própria, de propor ideias, de tomar posições, de fazer críticas e de recebê-las. Exige que nos exponhamos publicamente, oralmente e por escrito (...) para filosofar não se exige 
mais genialidade que a que se exige para ser astrônomo, antropólogo, engenheiro, cozinheiro ou jogador de basquete. Basta apenas que se tenha alguma inclinação, alguma capacidade e um certo amor pelo que se quer fazer. E é muito útil que se tenham professores que saibam ajudar-nos a percorrer o caminho escolhido. (Oswaldo Porchat)

A filosofia enquanto disciplina escolar possui uma trajetória bem peculiar no cenário nacional. Diversas leis regulamentaram sua oferta tornando-a facultativa, ora obrigatória. A mais recente e ainda em fase de concretização, a atual reforma do ensino médio que atende pela Lei $n^{\circ} 13.415$ de 16/02/2017, depende apenas da finalização sobre as discussões da Base Nacional Curricular Comum para estabelecer o novo destino da filosofia na educação básica: ela deverá ser oferecida em forma de "estudos e práticas" ao lado de educação física, arte e da sociologia. Sobre o que significa a oferta em forma de "estudos e práticas" a lei é omissa, menos evidente que a antiga estrutura disciplinar e reserva para a posteridade as discussões sobre a forma em que isso ocorreria nas escolas. O que temos de certeza é que a antiga estrutura disciplinar da filosofia não é mais uma garantia legal.

Para os recém-licenciados em filosofia, tal medida gerou um desânimo e constitui-se como um golpe na esperança da garantia de vagas em concursos e em postos de trabalho. Para tais profissionais, a desvalorização da filosofia ocorre devido a obrigatoriedade/ não obrigatoriedade no sistema de ensino, no qual foi usada de acordo com as determinações de cada época ${ }^{1}$. Para certa parte da comunidade dos educadores- filósofos e filósofas, a filosofia é transdisciplinar por natureza e seu confinamento enquanto disciplina não era ponto positivo na efetivação de sua transdisciplinaridade. Com certeza, será novo embate.

Os dispositivos e orientações institucionais ${ }^{2}$, assim como os livros didáticos aprovados pelo Ministério da Educação em 2015 conferem uma identidade da disciplina filosófica e seu ensino associadas à história do pensamento ocidental. Embora não aponte como diretiva inflexível que aquilo que tradicionalmente conhecemos como "História da Filosofia" seja o único compromisso curricular possível no ensino filosófico, deixa evidente que todo e qualquer diálogo deve ser feito a partir do que se entende como "História da Filosofia" e seu cânone. Diante disso, cabe observar que a força de tal afirmação se tornou o eixo direcionador dos currículos e livros didáticos de todo país. A grande questão que é colocada por autores como Renato Noguera (2014), Silvio Gallo (2013) e tantos outros, é que a "história da filosofia" tal como promovida pela tradição é alocada de forma monológica e pretensamente universal na tradição de pensamento ocidental.

Dito de outra forma: há um entendimento que o pensamento filosófico se restringe ao modo e a história do pensamento ocidental, excluindo-se dos currículos e dos livros didáticos (o que é reflexo dos próprios cursos de filosofia superior) outras formas de produção filosóficas, assim como a própria historicidade de cada modelo de racionalidade. Essa forma monolítica de racionalidade, segundo Renato Noguera (2014), está amparada em uma eurocentricidade e na continuidade de uma colonialidade do saber que prioriza o solo epistêmico europeu (e sua origem grega) como território exclusivo do pensamento filosófico. 
Diante disso, e o que de fato nos interessa nesse artigo, é tematizar uma certa identidade com que a filosofia se manifesta nos dispositivos e orientações educacionais dispostos até o momento e como, por meio do conceito de currículo menor, podemos desconstruir tal perspectiva, em uma aposta de educação filosófica comprometida com a diferença e a menoridade da atuação discente.

\section{Contextualizando a noção de menoridade}

No livro Kafka - Por uma literatura menor, Gilles Deleuze e Félix Guattari nos apresentam o conceito de "literatura menor". Esta não se refere a uma língua menor, mas, sim, ao que uma minoria faz em uma língua maior (DELEUZE e GUATTARI, 2014, p.35). De acordo com a perspectiva deleuze-guattariana, a literatura menor não se assemelha a esfera numérica, mas, a práticas minoritárias em uma língua menor, ou seja, tudo aquilo que foge à regra, ao que é estabelecido como modelo, as circunstâncias revolucionárias nas literaturas que fazem parte da língua que é determinada como maior, produzindo modificações.

Ainda de acordo com os autores referenciados, a literatura menor apresenta como características o forte coeficiente de desterritorialização; a ligação entre o individual e político e o valor coletivo. Deleuze e Guattari (2014) fazem uso do exemplo do impasse ao acesso à escrita pelos judeus de Praga para definir a desterritorialização da língua que ao se encontrarem diante da dificuldade de ter que escrever em alemão - que é a língua estabelecida como padrão naquele local - se veem perante a um sentimento de distanciamento da sua territorialidade local que é a República Checa, e ao mesmo tempo, a impossibilidade de escrever em alemão se apresenta como uma descaracterização cultural. Neste aspecto, o conceito de território se apresenta além do entendimento comum de uma simples área que demarca espaço entre as terras, porém, em uma visão ampla, que indica o lugar em que o homem está posto no mundo, representando as regras instituídas, e a desterritorialização, por sua vez, pressupõe uma fuga do território, "nos remete a buscas, a novos encontros e novas fugas. A literatura menor nos leva sempre a novos agenciamentos" (GALLO, 2013, p. 63), em que uma minoria dispõe de uma língua maior.

Nesse sentido, a desterritorialização de uma língua maior ocorre por
meio do uso "desobediente" que um grupo promove em meio a língua
padrão, formal, uma língua que congrega os ordenamentos e poderes
do discurso. Ao deslocar o uso, ao propor outros agenciamentos
ocorre um processo de desterritorialização, ao mesmo tempo que
territorializa um outro território. O agenciamento é uma expressão da
multiplicidade e efetuação do desejo, de caráter heterogêneo e que
se apresenta por meio das relações possíveis entre termos de natu-
rezas distintas. Para além das configurações das relações de força
que compõem o campo social, o agenciamento é inserção de uma
irregularidade disjuntiva nos alicerces do poder (ROSA, 2016, p.3). 
A segunda característica aponta uma ramificação política, devido a condição de vida dos sujeitos estar intimamente imbricada em questões políticas, tudo nas literaturas menores é político, o seu espaço exíguo faz que os casos individuais sejam políticos. Para Gallo (2013), o ato de ser é político e revolucionário em essência e implica em um desafio ao sistema instituído, ao contrário da maioridade que ao invés de estabelecer elos e agenciamentos está para promover interrupções e em territorializar-se nos sistemas das tradições a todo custo.

Sobre a terceira e última característica, no livro Kafka - Por uma literatura menor de Deleuze e Guattari, encontramos que:

É a literatura que se encontra encarregada positivamente deste papel e desta função de enunciação coletiva, e mesmo revolucionária: é a literatura que produz uma solidariedade ativa, malgrado o ceticismo; e se o escritor está à margem ou apartado de sua comunidade frágil, essa situação o coloca ainda mais em condição de exprimir uma outra comunidade potencial, de forjar os meios de uma outra consciência e de uma outra sensibilidade (2014, p. 37).

Para Deleuze e Guattari (2014), o escritor mesmo em posse de um atributo individual este não se apresenta no sentido próprio apenas de um ser, mas sim, como aquele que atinge ao geral em razão de que, ao escrever o que aborda reflete o coletivo do qual ele faz parte e tudo aquilo que ele diz ou faz presume um caráter intimamente político, que impulsiona o enunciado em que, o individual não se desliga do comum e sendo assim, tudo assume um valor coletivo.

Em suma, as noções de maior e menor representam uma relação estreita com os processos que permitem a marginalização por meio da normatização de modelos que são considerados vigentes. A literatura ao estabelecer um uso menor dentro de uma língua maior promove desvios diante do que é instituído como norma, concebendo novas possibilidades, sem o caráter de existência de regulamentações, padrões ou condutas, oportunizando deslocamentos, que são operados pelos grupos marginalizados.

\section{Por uma menoridade educacional}

Deleuze juntamente com Guattari na obra O que é a filosofia? apresentaram a noção da filosofia como uma criação conceitual: "Simplesmente chegou a hora, para nós, de perguntar o que é a filosofia. Nunca havíamos deixado de fazê-lo, e já tínhamos a resposta que não variou: a filosofia é a arte de formar, de inventar, de fabricar conceitos." (2000, p.10). Apesar de Deleuze não ter escrito especificamente sobre a educação, ele teve seus pensamentos e conceitos deslocados para o campo educacional e aqui trataremos destes deslocamentos sobre a perspectiva do filósofo brasileiro Silvio Gallo.

De acordo com Deleuze, devido justamente ao seu caráter criativo, a filosofia não deve se restringir simplesmente as características de reflexiva, contemplativa e comunicativa visto que, isto representaria uma limitação da filosofia. $E$ ao desenvolver a filosofia como uma criação de conceitos, tal como a vida ativa e não 
contemplativa, o autor supracitado rompe com uma tradição filosófica que desde os primórdios acredita no pensamento como um motor e um ato de contemplação.

Desta maneira, os conceitos não estão dispostos para serem contemplados ou encontrados, mas sim, para serem criados, produzidos, inventados e devem ser feitos de maneira imanente. Gallo em Metodologia do ensino de filosofia - Uma didática para o ensino médio reitera que:

Os conceitos são criados a partir de problemas, colocados sobre um plano de imanência. Esse plano é o próprio solo dos conceitos e, portanto, da filosofia, e é traçado pelo filósofo tendo como elementos o tempo e o lugar em que vive, suas leituras, suas afinidades e desavenças. É nesse plano que surgem os problemas, e são os problemas que movem a produção conceitual (GALLO, 2014, p. 63).

Ao aproximarmos os conceitos de Deleuze e Guattari para o âmbito educacional, mais especificamente no que concerne a filosofia dentro da educação básica no Brasil, podemos perceber que a disciplina foi construída sob uma visão daquela que detém o caráter reflexivo e contemplativo, o que de acordo com os autores referenciados gera um empobrecimento e para que o porvir seja frutífero é preciso que haja espaços de criações conceituais. Dentro desta perspectiva é urgente "que busquemos uma filosofia da educação criativa e criadora, que não seja tão inócua. Ela deve ser perigosa, deve ser o veneno e o remédio. É necessário que corramos o risco, que mergulhemos nesse caos povoado de opiniões" (GALLO, 2013, p. 58-59).

Silvio Gallo (2013), viabiliza um deslocamento do conceito de literatura menor trazido no livro de Gilles Deleuze e Félix Guattari, Kafka- por uma literatura menor, para o campo educacional, produzindo a noção de educação maior e educação menor. A educação maior seria a das políticas públicas nacionais, dos parâmetros, das diretrizes, que são construídas e estabelecidas em todo país a serviço do poder e a educação menor é aquela que se revolta diante do que é estabelecido como vigente e resiste ao que é posto e determinado. (ROSA, 2016, p.7).

Deste modo, a educação menor ocorre nas possibilidades do ato educativo militante dos discentes na sala de aula, produzindo novas possibilidades, fazendo com que seja um lugar de criação e de compartilhamento em que, militar não é doutrinar, mas assumir o lugar ético e político de todo ato educativo. Dentro das três características principais a serem observadas na literatura menor referidas anteriormente neste artigo ao serem deslocadas por Gallo para o âmbito educacional percebemos que, a desterritorialização se apresenta como um modo de fugir daquilo que é instituído pela educação maior. Isso equivale a dizer que o movimento desterritorializante na educação é experimentado como uma descaracterização do plano identitário do currículo de filosofia na educação básica.

Nesse sentido, no que concerne às orientações curriculares e os livros didáticos de filosofia, se percebe que o ensino dessa disciplina perpassa somente no estudo da produção filosófica ocidental e, por meio disso, se constrói uma imagem do ensino de filosofia na educação básica como uníssono e monoracional. Ou seja, a filosofia é vista como totalidade única e não como pluralidade. Entendemos a filosofia como uma 
experiência do pensamento fundada nas culturas, como preconiza os pressupostos de uma filosofia como uma experiência cultural, e dessa forma, há filosofias, no plural.

\begin{abstract}
Desterritorializar os princípios, as normas da educação maior, gerando possibilidades de aprendizado insuspeitadas naquele contexto. Ou, de dentro da máquina opor resistência, quebrar os mecanismos, como ludistas pós-modernos, botando fogo na máquina de controle, criando novas possibilidades. A educação menor age exatamente nessas brechas para, a partir do deserto e da miséria da sala de aula, fazer emergir possibilidades que escapem a qualquer controle (GALLO, 2013, p. 67).
\end{abstract}

Aqui cabe, pois destacarmos que dentro desta ótica do processo de ensino/aprendizagem determinado pela educação maior, que o professor não tem como controlar o que o aluno irá aprender, não há como medir nem muito menos estabelecer métodos que sejam efetivamente eficientes. Para que a aprendizagem seja satisfatória devemos levar em conta o que o estudante está fazendo com tudo aquilo que está sendo desenvolvido no espaço escolar e para além dele, imbrica em como o conhecimento está sendo organizado.

Em conformidade com a segunda característica da ramificação política, como nas literaturas, toda educação também se faz como um ato político e sobretudo a educação menor por se apresentar como um ato de resistência dedicando-se aos elementos que surgirão do cotidiano. Em Deleuze e Educação, Gallo afirma que:

\begin{abstract}
A ramificação política da educação menor, ao agir no sentido de desterritorializar as diretrizes políticas da educação maior, é que abre espaço para que o educador militante possa exercer suas ações, que se circunscrevem num nível micropolítico. A educação menor cria trincheiras a partir das quais se promove uma política do cotidiano, das relações diretas entre indivíduos, que por sua vez exercem efeitos sobre as macrorrelações sociais. Não se trata, aqui, de buscar as grandes políticas que nortearão os atos cotidianos, mas sim de empenhar-se nos atos cotidianos. Em lugar do grande estrategista, o pequeno "faz-tudo" do dia a dia, cavando seus buracos, minando os espaços, oferecendo resistências (GALLO, 2013, p. 68).
\end{abstract}

Deste modo, a educação menor se manifesta como um rizoma. Deleuze e Guattari, em Mil Platôs (2009), propõem a percepção do rizoma como uma realização das multiplicidades, que ecoam em ressonância e fluidez, sem sujeitos ou identidades. O rizoma é uma proposta de experimentação do mundo não hierarquizada que conserva sua intensidade e, produz conceitos.

Assim como na terceira característica das literaturas, na educação a todo ato atribuise um valor coletivo no qual, "toda singularização será, ao mesmo tempo, singularização coletiva" (GALLO, p.68, 2013). Cada escolha ou ação dos indivíduos envolvidos neste processo estará produzindo afetos - falamos aqui, no sentido próprio da palavra de afetar, pois todos os vínculos que são estabelecidas pelos sujeitos que se encontram inseridos no 
campo educacional promovem uma conexão direta, onde as suas ações produzem efeitos entre eles. O pensamento deverá ser percebido como uma caixa de ferramentas, no qual o ato de aprender seja visto como um trabalho de criação e também de produtividade. A respeito da educação menor, na obra Deleuze e Educação, Gallo compreende que devemos:

Educar com a fúria e a alegria de um cão que cava seu buraco. Educar escavando o presente, militando na miséria do mundo, de dentro de nosso próprio deserto. Esse é um dos resultados possíveis de nosso encontro com a filosofia de Deleuze; essa é uma das possibilidades de um devir- Deleuze na educação (Gallo, 2013, p. 70).

Percebemos que a filosofia de Gilles Deleuze tem a capacidade de afetar a maneira como pensamos a educação e a própria filosofia da educação, fazendo com que deixemos de perceber a realidade como uno, mas sim, como uma produção de múltiplas realidades, como multiplicidade pura em que, ao mergulharmos no caos e na criação de conceitos estamos diante de uma posição de enfrentamento para com os problemas elaborados na realidade.

Podemos entender que a educação menor implica na aposta por multiplicidades, em razão de que, o mundo é por si múltiplo e não possui uma única realidade, os conhecimentos são produzidos através de conexões rizomáticas, como afirmam os autores supracitados, " o rizoma nele mesmo tem formas muito diversas, desde sua extensão superficial ramificada em todos os sentidos até suas concreções em bulbos e tubérculos” (1995, p. 22), que destarte, vão gerando um emanharado de conhecimentos. Gallo (2013) nos leva a pensar a educação e consequentemente o currículo, sobre a perspectiva rizomática, no sentido de que, se deve cogitar para além do que é estabelecido, do que é especificado para se seguir, sem hierarquias, desfazendo a concepção tradicional para que o aluno possa dispor de possibilidades, dando a estes elementos, possibilitando o múltiplo para além da reprodução de conhecimentos.

\section{O que pode um currículo menor?}

Compreendemos que o ensino de filosofia deve ser um espaço que possibilite diálogos, diante disto, em um país como o Brasil, é de cunho substancial que a filosofia não se limite apenas a reproduzir a sua história por meio da perspectiva ocidental, mas sim, que fomente inquietações a respeito das diversas filosofias. Deste modo, os estudantes poderão compreender que a diversidade pode se fazer presente através, por exemplo, do conhecimento sobre a filosofia africana ou dos povos originários. Desta maneira, como o ensino de filosofia pode contribuir na promoção dos diversos saberes?

Em 2008, a filosofia retornou ao currículo como obrigatória juntamente com a sociologia por meio da Lei de $n^{\circ} 11.684$ e com ela surgiram parâmetros e orientações curriculares nacionais para o seu ensino como uma maneira de garantir um bom desenvolvimento das aulas de filosofia e como direcionamento para os docentes. Nas orientações curriculares para o Ensino Médio fica determinado que: 
É salutar, portanto, para o ensino da Filosofia que nunca se desconsidere a sua história, em cujos textos reconhecemos boa parte de nossas medidas de competência e também elementos que despertam nossa vocação para o trabalho filosófico. Mais que isso, é recomendável que a história da Filosofia e o texto filosófico tenham papel central no ensino da Filosofia, ainda que a perspectiva adotada pelo professor seja temática, não sendo excessivo reforçar a importância de se trabalhar com os textos propriamente filosóficos e primários, mesmo quando se dialoga com textos de outra natureza, literários e jornalísticos, por exemplo - o que pode ser bastante útil e instigante nessa fase de formação do aluno. Porém, é a partir de seu legado próprio, com uma tradição que se apresenta na forma amplamente conhecida como História da Filosofia, que a Filosofia pode propor se ao diálogo com outras áreas do conhecimento e oferecer uma contribuição peculiar na formação do educando (MEC, 2006, v. 3, p. 27).

Percebemos que por meio destas Orientações Curriculares Nacionais, os elementos centrais para o ensino de filosofia são a história da filosofia e os textos filosóficos, ou seja, o ensino de filosofia deverá ser realizado apresentando como foco a sua história, por meio de uma tradição. Sabemos que os currículos das escolas de uma maneira geral, assim como os livros didáticos, se baseiam preferivelmente pela filosofia ocidental, criando desta maneira, uma identidade baseada na filosofia ocidental para o ensino médio.

De acordo com Noguera (2014), o estabelecimento do pensamento filosófico ocidental como cânone gerou uma desigualdade epistêmica, que ocorreu devido às geopolíticas que foram estabelecidas por meio de discursos racistas que insistem em posicionar a Europa como o centro do mundo. $O$ autor supracitado apresenta a ideia de colonialidade, que implica na supremacia e no predomínio de alguns conhecimentos em detrimento de outros que não foram produzidos dentro do espaço geopolítico instituído como modelo, neste caso o ocidental. Para Noguera:

Se a filosofia ocidental tem historicamente sido construída por uma visão etnocêntrica - no caso, o eurocentrismo ou eurocentricidade -, essa visão tenderia a excluir outros estilos, linhas e abordagens filosóficos, negando a legitimidade epistemológica dessas abordagens filosóficas que não são ocidentais (NOGUERA, 2014, p. 28).

Neste sentido, o ensino de filosofia se apresenta de um modo restrito, ao se limitar em apresentar uma única filosofia, se baseando apenas na tradição filosófica ocidental, privando o conhecimento das diversas formas de pensamento. Diante da sua atuação enquanto professor e filósofo, ao vivenciar os problemas que se encontram dispostos no âmbito escolar, o docente deve optar por uma posição sobre a filosofia. Escolher uma experiência de pensamento que the ajude a pensar uma educação filosófica pautada pela ética e pela valorização da diversidade, aqui aproximada da própria diferença minoritária no currículo oficial.

A proposta busca fundamentalmente evidenciar que cada grupamento humano que vive e já viveu ofereceu respostas diversificadas, diante de perguntas diversificadas e por meio 
de lógicas e racionalidades diferentes, mas não hierarquicamente posicionadas. É preciso que o ensino filosófico encontre sua "virada" antropológica e promova uma abertura qualificada e dialógica ao múltiplo em suas diversas manifestações. Mas como isto pode ser feito? Fazendo uso do conceito apresentado por Gallo (2013), o professor militante é aquele que opera ações de transformação seja na sala de aula, nas relações em que estabelece, no ambiente de trabalho enfim, no social. A militância ocorre por meio de uma luta cotidiana na produção de possibilidade do novo, em uma ação que nunca é isolada, mas sim, um ato coletivo, no qual cada feito gera a abertura a novas possibilidades. Para Renato Noguera (2014), negar uma relação polissêmica e polidiálogica no ensino filosófico é aceitar a reprodução de visões racistas e preconceituosas sobre as culturas africanas e afrodiaspóricas, assim como os demais núcleos sapienciais humanos. Nesse sentido, o ensino filosófico na educação básica pode contribuir de maneira significativa para pluralizar a experiência do pensamento, assim como viabilizar uma mirada descolonizante nas relações e referenciais de ensino de filosofia, produzindo novas subjetividades e outros jogos de afetos no campo da aprendizagem. Esta perspectiva reitera a importância de um processo de ensino e aprendizagem da sensibilidade, onde seja percebida a importância do aprender a perceber, para que se possa tocar a cada um dos indivíduos. Desta maneira, o professor militante é aquele que pode ativar um devir ${ }^{3}$ no currículo. Deleuze e Guattari reiteram que:

É que devir não é imitar algo ou alguém, identificar-se com ele. Tampouco é proporcionar relações formais. Nenhuma dessas duas figuras de analogia convém ao devir, nem a imitação de um sujeito, nem a proporcionalidade de uma forma. Devir é, a partir das formas que se tem, do sujeito que se é, dos órgãos que se possui ou das funções que se preenche, extrair partículas, entre as quais instauramos relações de movimento e repouso, de velocidade e lentidão, as mais próximas daquilo que estamos em vias de nos tornarmos, e através das quais nos tornamos. É nesse sentido que o devir é o processo do desejo (DELEUZE; GUATTARI, 1997, p. 64).

Dentro deste contexto, um ato de menoridade é aquele que desloca os outros saberes que não são possíveis de se pensar em um currículo que só apresenta a tematização da história da filosofia ocidental como elemento central. Sobretudo, devemos perceber que o currículo não é algo pronto e acabado, em que a sala de aula reduz-se a reproduzir o que é colocado de um modo governamental, estabelecido pela instituição de acordo com as determinações legais, mas sim como um espaço que está em constante construção e nesta perspectiva é possível que sejam criados mecanismos que possibilitem uma relação dialógica e pluriversal.

Dessa forma, um currículo filosófico em devir revolucionário e como multiplicidade precisa destruir a imagem da representação do pensamento, precisa instaurar a multiplicidade para metamorfosear a sua; colidir e se conectar com outros devires. Trata-se de "deseducar" o processo do pensamento com a violência criativa de outras formas de pensar. Tal violência também pode (e deve) surgir por meio 
da filosofia ocidental, mas o diálogo poliracional enfatiza e desnaturaliza a preconcepção que somente é válida e capaz de se universalizar o pensamento ocidental.

Os dispositivos curriculares de filosofia devem apresentar diversos centros temáticos, pois ao colocar um como superior aos demais, as outras possibilidades se encontram restritas, assim, "não trata-se de uma recusa da história da filosofia (ocidental); mas, o reconhecimento que no campo filosófico não devemos ficar restritos a dogmas e transformação de enunciados em clichês intelectuais" (NOGUERA, 2016, p. 403).

É necessário que ocorra uma linha de fuga no currículo para que o ensino de filosofia contemple na construção de um saber múltiplo. A linha de fuga não diz respeito a renúncia. Ao contrário, é uma categoria ativa que promove rupturas, produz frestas, buracos no conjunto dos ordenamentos de qualquer natureza e opera mediante o princípio de romper, fazer vazar. (ROSA, p.79, 2017).

Pensando sobre esta perspectiva, porém voltada para educação, podemos refletir sobre como seria fugir deste território em que o currículo está instituído, ao mesmo tempo criando outro sem deixar de estar presente nele. Criar linhas de fuga no currículo de filosofia seria um devir, um ato de desterritorialização, não se limitando em conceber outros territórios e outras formas de saber, mas sim, indicando novas possibilidades, instituindo linhas de fuga. Uma filosofia comprometida com a afirmação do pensamento dos que foram estigmatizados como outros.

Se o currículo que está disposto não atende à pluriversalidade do saber, o professor dispõe de possibilidades para fazer com que atenda no estabelecimento de uma relação menor, dialógica e de resistência ademais dos dispositivos e orientações curriculares, construindo possibilidades de problematização, fomentando a criação.

A filosofia possui o germe da inquietação e apresenta um caráter crítico, argumentativo e dialógico, capaz de gerar novas possibilidades, junto a uma educação que valorize o pensar, auxiliando na mudança dos paradigmas que já se encontram determinados, favorecendo para que a educação não se torne acrítica, se restringindo a transmissão dos conhecimentos, em razão de que a escola deve ser um espaço que promova a desnaturalização dos pensamentos. Para esta ideia não se tornar uma utopia, é necessário que haja um deslocamento no currículo, oportunizando um devir menor, para que a produção filosófica de outras sapiências seja incentivada, favorecendo a história e cultura dos diversos povos e as suas formas de saber.

A realização de uma menoridade no currículo, seria a produção de novas possibilidades, geradas no cotidiano por meio dos atos de resistência, no qual as grandes determinações que são instituídas na sociedade fazem sobre a educação a saber, as políticas públicas, parâmetros e diretrizes que regem o que deve ser feito e como se deve agir com as disciplinas inseridas no processo educacional. Toda e qualquer lei representa a maneira como as coisas devem acontecer, porém cada professor detém da possibilidade de subverter aos ordenamentos discursivos e as estruturas do poder. Como posição filosófica, ética e política pois, compreendemos que tais perspectivas são indissociáveis na arquitetura e proliferação dos saberes. Afinal, um 
devir-menor no currículo busca romper com a ideia de unicidade e identidade na esfera curricular do ensino de filosofia, se situando diante da luta e do enfrentamento a tudo aquilo que desfavorece a educação, no sentido da promoção de distanciamento das culturas e da produção de estereótipos e protótipos. Contrariamente à educação menor implica em um ato minoritário para resistir em favor das multiplicidades, instaurando o novo, possibilitando a abertura de novas formas de se fazer o ensino de filosofia e também o processo educacional.

\section{Considerações finais}

Em suma, acreditamos que trabalhos desta natureza podem nos levar a refutar o que se encontra como um modelo estabelecido na sociedade, gerando estranhamento para desnaturalizar o pensamento. Neste caso, nos referimos ao currículo eurocentrado que foi difundido e que acabamos por aceitar naturalmente nas escolas e deste modo, reproduzimos maneiras de se comportar, costumes e saberes como sendo superiores e os mais adequados.

A ausência das diversas culturas no currículo é algo perceptível e com o ensino de filosofia não é diferente. Nas Orientações Curriculares Nacionais para o Ensino Médio (OCNEM), que foi publicada em 2006, anteriormente a promulgação da lei 11.645/08, que tenciona a inclusão da história dos povos ameríndios, porém, posteriormente a publicação da lei 10.639/03, que estabelece a aplicação do estudo da história e cultura Afro-Brasileira e Africana nas escolas, podemos perceber que o documento não faz nenhuma referência a esta temática no capítulo delimitado a filosofia.

De acordo com Noguera (2014), para o ensino de filosofia conseguir atender as exigências das demandas legais no que consiste as relações étnico-raciais "[...] deve estar comprometido com um corpo de ações afirmativas no campo epistêmico. Em outros termos, as atividades docentes e discentes de filosofia devem ser permeadas por ações afirmativas epistemológicas" (p. 99), para que possamos diminuir as diferenças entre os povos e as suas culturas.

No ensino filosófico a mulher não existe, o negro e negra não existem, nem existem as formas de pensar das outras culturas. Nessa relação, a experiência educativa é uma busca constante por uma inquietação de fundo ético e epistemológico, que por meio da diferença possibilita entender a educação e o ensino filosófico sem que se apague a existência dos outros. A supremacia e o caráter de universalidade sobre a filosofia ocidental dentro do currículo do ensino básico deve ser questionada em favor da multiplicidade e da diversidade. Isto não significa substituir, mas sim, levar em consideração as outras sapiências, contemplando as diversas formas de saber.

\section{Referências}

ALVES, D. J. A. Filosofia no Ensino Médio - ambiguidades e contradições na LDB. Campinas, SP: Ed. Autores Associados, 2002.

BRASIL. Ministério de Educação e Cultura. LDB - Lei n 9394/96, de 20 de dezembro de 1996. Estabelece as diretrizes e bases da Educação Nacional. Brasília: MEC, 2006. 
. Constituição (1988). Constituição da República Federativa do Brasil. Brasília, DF: Senado, 1988.

. Lei 10.639/2003, de 9 de janeiro de 2003. Altera a Lei $n^{\circ}$ 9. 394, de 20 de dezembro de 1996. Diário Oficial da União, Poder Executivo, Brasília.

Lei 11.645/08 de 10 de março de 2008. Diário Oficial da União, Poder Executivo, Brasília.

Orientações curriculares para o Ensino Médio. Brasília, DF: Ministério da Educação, 2006, vol. 3.

BRASIL. Lei $\mathbf{n}^{\circ}$. 13.415, de 16 de fevereiro de 2017. Brasília, 2017. Disponível em: http:// www.planalto.gov.br/ccivil_03/_ato2015-2018/2017/Lei/L13415.htm. Acesso em: 18 fev. 2017.

CERLETTI, Alejandro. O ensino de filosofia como problema filosófico. Belo Horizonte: Autêntica, 2009.

DELEUZE, Giles; GUATTARI, Félix. Kafka: por uma literatura menor. Tradução Cíntia Vieira da Silva. Belo Horizonte: Autêntica, 2014.

Mil Platôs: Capitalismo e esquizofrenia. Vol. 1. Tradução Suely Rolnik. São Paulo: Editora 34, 2012.

. Mil Platôs: Capitalismo e esquizofrenia. V. 4. Tradução Suely Rolnik. São Paulo: Editora 34, 2012.

O que é filosofia? São Paulo: Editora 34, 2000.

FAGUNDES, N. C.; FRÓES BURNHAM, T. Transdisciplinaridade, multirreferencialidade e currículo. FACED, Salvador: Faculdade de Educação da UFBA, N. 5, 2001, p. 39-55.

GALLO, Sílvio. Deleuze \& Educação. Belo Horizonte. Autêntica, 2013.

. Em torno de uma Educação Menor. Revista Educação e Realidade. 2002, p. 169-178.

Metodologia do ensino de filosofia - Uma didática para o ensino médio. Campinas - SP: Papirus, 2012.

MOREIRA, Antônio Flavio Barbosa. Indagações sobre o Currículo: Currículo, Conhecimento e Cultura. Organização do documento - Jeanete Beauchamp, Sandra Denise Pagel, Aricélia Ribeiro do Nascimento - Brasília: Ministério da Educação, Secretária de Educação Básica, 2008.

NOGUERA, Renato. Introdução à Filosofia a partir da história e culturas dos povos indígenas. Rio de Janeiro: Revista Interinstitucional, 2016.

. O ensino de filosofia e a Lei 10.639. Rio de Janeiro: Pallas, 2014. 
ROSA, Francis Mary Soares Correia da. A literatura menor em Deleuze e Guattari: por uma educação menor. Educação (UFSM), v. 41, n. 3, p. 685-696, 2016.

ROSA, Francis Mary Soares Correia da. Tekoá - Por um devir-onça na literatura indígena. 1. ed. Düsseldorf: Novas Edições Acadêmicas, 2017. v. 1.

SILVA, Tomás Tadeu da. Alienígenas na sala de aula. Petrópolis, RJ: Vozes, 1995.

Documentos de Identidade - Uma introdução às teorias do currículo.

Autêntica: Belo Horizonte, 2015.

. O Currículo como Fetiche - a poética e a política do texto curricular.

Autêntica: Belo Horizonte, 2010.

SCHOLLHAMMER, Karl Erik. As práticas de uma língua menor: reflexões sobre um tema de Deleuze e Guattari. Ipotesi, Juiz de Fora, v. 5, n. 2, p. 59-70, 2001.

ZOURABICHVILI, François. O vocabulário de Deleuze. Tradução André Telles. Rio de Janeiro: Cidade: Ifch-unicamp, 2004.

\section{Notas}

1 O ensino escolar no Brasil sempre teve a sua estrutura e o seu papel condicionado ao modelo econômico e político vigente em cada momento da história nacional; consequentemente, a cada redirecionamento político e econômico havia uma nova reestruturação do ensino escolar, para adaptá-lo aos interesses dos "novos senhores" do poder. (ALVES, 2002, p. 35).

${ }^{2}$ Compreende-se tais dispositivos para análise: as Orientações Curriculares Nacionais, Parâmetros Curriculares Nacionais e Pcn +. No Plano Nacional do Livro Didático na área de Filosofia (2015), os seguintes livros foram aprovados: Filosofando - Introdução à Filosofia; Filosofia: Experiência do Pensamento; Filosofia: Por uma Inteligência da Complexidade; Fundamentos de Filosofia; e Iniciação à Filosofia.

${ }^{3}$ Para Deleuze, o devir "é nunca imitar, nem fazer como, nem se conformar a um modelo, seja de justiça ou de verdade". (ZOURABICHVILI, 2004, p.24).

\section{Correspondência}

Francis Mary Soares Correia Da Rosa - Rua Rouxinol, 115, Imbui, Instituto Federal de Educação, Ciência e Tecnologia Baiano, IF Baiano - Campus Xique-xique, CEP 41.745-003, Salvador, Bahia, Brasil.

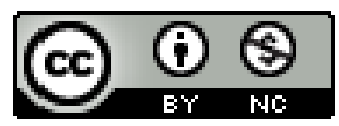

This work is licensed under a Creative Commons Attribution-NonCommercial 4.0 International (CC BY-NC 4.0) 